\title{
Pesquisa em Políticas Educacionais e Gestão da Educação Básica: produções discentes dos programas de pós-graduação em educação da região Sul (2000-2010)
}

Research in Educational Policies and Management of Basic Education: students' productions in graduate programs in education of Brazilian South region (2000-2010)

Investigación en Política Educativa y Gestión de la Educación Básica: producciones de los programas de postgrado en educación en la región Sur de Brasil (2000-2010)

Nalú Farenzena'

Caroline Cristiano Cardoso ${ }^{2}$

\section{Resumo}

O objetivo do texto é apresentar um panorama da produção acadêmica discente sobre gestão da educação e políticas educacionais na educação básica dos programas de pós-graduação em educação da região sul do Brasil, considerando o período 2001-2010. Antecedendo a apresentação do panorama, é contemplada uma síntese de alguns estudos sobre a produção acadêmica na mesma área. A produção é categorizada a partir dos seguintes recortes: tipo de pesquisa (tese ou dissertação); por instituição; grandes temáticas que foram objeto de estudo; detalhadas conforme o território a que se referem. Verificou-se uma produção crescente na área, concentrada na categoria temática políticas públicas, com predominância do foco no território município.

Palavras-chave: Políticas públicas de educação; Gestão da educação; Pesquisa em política educacional; Pesquisa em educação região sul. 


\section{Abstract}

The objective of the text is to present a panorama of the academic production of students on education management and the educational policies in the basic education of the postgraduate programs in education in the South of Brazil, considering the period of 2001-2010. Preceding the presentation of the panorama, a summary of a few studies on academic production in the same area is contemplated. The production is categorized based on the following delimitations: type of research (thesis or dissertation); by institution; major themes that have been the object of study; detailed according to the territory in which they refer to. A growing production in this area was verified, focused on the public policies topic category, with predominant focus on the county territory.

Keywords: Public policies of education; Education management; Research in educational policy; Research in education in the Brazilian South region.

\section{Resumen}

El objetivo del trabajo es presentar una visión general de la producción académica sobre la gestión de la educación, políticas educativas en la educación básica, hecha en los programas de postgrado en educación en el sur de Brasil, considerando el período 2001-2010. Antes de presentar el panorama, se contempla un resumen de algunos estudios sobre la producción académica en el mismo tema. La producción está categorizada por los siguientes cortes: tipo de investigación (tesis o tesina); institución; los temas principales que se estudiaron; se detallan como el territorio al que se refieren. Se ha verificado una producción cada vez mayor en la tematica, concentrada en la categoria políticas públicas, y principalmente se centran en el territorio del municipio.

Palabras-clave: Políticas públicas de educación; Gestión de la educación; Investigación en política educative; Investigación en la region sur de Brasil.

Elaboramos um mapeamento sucinto da produção acadêmica dos programas de pós-graduação da região sul do Brasil sobre gestão da educação e políticas educacionais, com as seguintes balizas: período 20002010; somente dissertações e teses de programas de pós-graduação em educação que tiveram como objeto a educação básica. Esse mapeamento abrange quantitativos de produção com os seguintes recortes: tipo de pesquisa (tese ou dissertação), por instituição; grandes temáticas que foram objeto de estudo, detalhadas conforme o território a que se referem. Por grandes temáticas foram definidas: políticas públicas; gestão de sistemas ou redes de ensino; gestão de escolas; direito à educação; legislação e normas educacionais. Vinculados a cada temática foram especificados os territórios aos quais as pesquisas lançaram seus olhares: escola; município, estado (unidade da federação); nacional; nacionais.

Antes de entrar na apresentação das características e dos achados de nosso estudo, resenhamos três produções que se debruçaram sobre o tema da pesquisa e da produção em política educacional e/ou gestão da educação. Isso porque são obras que inspiraram as categorizações que realizamos, assim como nos forneceram alguma medida de comparação de resultados.

Nossa sistematização evidenciou o crescimento constante no número de teses e dissertações sobre temas de política e gestão da educação básica no período, o que se explica, principalmente, pelo próprio aumento no número de programas de pós-graduação em educação na região. Localizamos um total de 469 trabalhos. Como o número de cursos de mestrado é bem maior que o de cursos de doutorado, obviamente predomina largamente o número de dissertações (430), mas o número de teses cresceu bastante no período. No que concerne às temáticas, dentro de política e gestão da educação básica, sua incidência, pela ordem, foi a seguinte: políticas 
educacionais, gestão da escola, gestão de sistema/rede de ensino, direito à educação, legislação e normas educacionais. Quanto aos territórios, o quantitativo de estudos sobre municípios foi o maior, seguido de estado, escola, espaço nacional e, por último, apenas três estudos de caráter comparativo envolvendo mais de um país. Encontramos uma produção crescente, com escopos e subtemas diversos, e ramificada do ponto de vista teórico-metodológico. Esse arranjo incita a pensar possíveis especificidades teóricas dentro do tronco comum tradicional chamado de política e gestão da educação. Não vamos sugerir que especificidades seriam essas, apenas faremos a provocação de que seria oportuno discuti-las.

\section{Estudos e reflexões sobre a produção acadêmica em gestão e políticas educacionais}

Optamos por resenhar aqui três publicações que têm como objeto a produção acadêmica em gestão e políticas educacionais. As duas primeiras são do tipo estado da arte. Foram escolhidas pelo significativo número de trabalhos contemplados. A terceira é uma reflexão de ordem mais geral sobre pesquisas em política educacional nos anos mais recentes e decidimos sintetizar alguns de seus conteúdos pelo entendimento de que faz uma avaliação que entra no debate das perspectivas teórico-metodológicas para avançar na produção de conhecimento na área ${ }^{3}$.

Entre 1998 e 1999, a Associação Nacional de Política e Administração da Educação (Anpae) desenvolveu a pesquisa O estado da arte em política e gestão da educação no Brasil: 1991 a 1997, cujos resultados foram publicados em Wittmann e Gracindo (1999). O objetivo da pesquisa foi o de "contribuir para o avanço do conhecimento relevante na área da gestão da educação e consolidar sua base nacional de articulação e intercâmbio sistemáticos entre pesquisadores na área" (WITTMANN e GRACINDO, 1999, p. 11).

A base da análise foi constituída de resumos de dissertações, teses e relatórios de pesquisa. A par da definição inicial, pela equipe de pesquisadores, de dois grandes conjuntos - política e gestão da educação -, os textos, numa quantidade final de 922, foram enquadrados em onze categorias temáticas.

Das 922 pesquisas analisadas, $70 \%$ foram alocadas em cinco das categorias temáticas: 143 em profissionais da educação; 130 em políticas de educação; 134 em gestão da escola; 114 em escolas, instituições educativas e sociedades; 98 em gestão da universidade. Financiamento da educação, público e privado na educação, assim como planejamento e avaliação educacionais, foram as temáticas com menos trabalhos.

Outras peculiaridades do conjunto das pesquisas foram as seguintes: predominaram as dissertações de mestrado (64\%), seguidas de pesquisas docentes (25\%) e teses de doutorado (11\%); a distribuição regional foi marcada pela concentração dos programas de pós-graduação no sudeste, onde foram produzidas $51 \%$ das produções em política e gestão da educação examinadas, seguindo-se $22 \%$ no sul, 17\% no centro-oeste, 8\% no nordeste, 0,5\% no norte, 0,8\% inter-regional e 0,2\% com a participação de instituições do exterior. A configuração da distribuição regional variou no período estudado: em 1991, a participação da produção do sudeste representava $64 \%$ do total, proporção que decresceu no período, com aumento daquelas do sul e do centro-oeste ${ }^{4}$.

\footnotetext{
3 Ressalvamos que há uma série de publicações importantes que mapeiam a produção em veículos de difusão da pesquisa política e gestão da educação ou que se preocupam em indicar perspectivas teórico-metodológicas promissoras para superar limitações (constatadas em estados da arte ou por meio das experiências de leitura dos pesquisadores). Correndo o risco de deixar de fora parte significativa de obras desses dois tipos, penso serem oportunas algumas indicações. Sobre produção do conhecimento em administração ou gestão da educação ou escolar: Azevedo e Aguiar (2001); Castro e Werle (2004); Pereira e Andrade (2005); Sander (2006); Maia (2008); Souza (2006 e 2008). Sobre produção do conhecimento em políticas educacionais: Santos e Azevedo (2005); sobre limitações da produção acadêmica brasileira em políticas educacionais e indicações de perspectivas teórico-metodológicas para superar essas limitações: Mainardes, Ferreira e Telo (2012); Martins, (2011) e também o texto de Barreto (2009) comentado mais adiante nessa seção.

4Seria muito oportuno que uma pesquisa com este escopo pudesse ser feita nos dias atuais, em continuidade e na linha de atualização e aperfeiçoamento, pois algumas curiosidades são suscitadas pelo estado da arte realizado na década de 1990. Será que mudou a distribuição de temáticas? Será que a categorização temática continua sendo adequada? Será que mudou a distribuição regional? Cresceu o número de pesquisas inter-regionais? Mudaram as proporções entre os diferentes tipos de produção (dissertação, tese e pesquisa dos docentes)? Quais elementos contextuais influenciaram as inflexões ou permanências na produção em política e gestão da educação no país? Quiçá a própria Anpae possa tomar a iniciativa e coordenar uma pesquisa em rede nessa perspectiva.
} 
A pesquisa que descrevemos na continuidade menciona explicitamente seu diálogo com o estado da arte acima referido: trata-se de outra investigação do tipo estado da arte, que sistematizou a produção científica de 2000 a 2008, sobre o tema da gestão, da autonomia e do funcionamento de órgãos colegiados, restrita ao espaço unidade escolar. Foi realizada entre 2009 e 2010, no âmbito do Departamento de Pesquisas Educacionais da Fundação Carlos Chagas, sob a coordenação de Ângela Maria Martins. Conforme Martins e Silva (2010, p. 423), "o levantamento buscou compreender e identificar de que forma os estudiosos de políticas públicas vêm analisando a gestão de escolas, os órgãos colegiados e seu papel na constituição da autonomia escolar".

No mesmo artigo citado, são explicitadas as perguntas que guiaram a pesquisa:

Quais regiões do país concentram maior número de estudos sobre o tema? Quais são os focos de interesses das investigações? Em torno de quais categorias essas pesquisas poderiam ser agrupadas? Predominam estudos empíricos ou teóricos? Quais as perspectivas metodológicas utilizadas? As pesquisas esclarecem os procedimentos adotados? (MARTINS E SILVA, 2010, p. 423).

Esse estado da arte envolveu o exame de 753 fontes documentais, abrangendo os seguintes subconjuntos: (1) 406 teses e dissertações; (2) anais das reuniões anuais da Associação Nacional de Pós-Graduação e Pesquisa em Educação (Anped) ${ }^{5}$ e dos simpósios bianuais da Associação Nacional de Política e Administração da Educação (Anpae); (3) artigos de periódicos nacionais. Resultados do levantamento foram publicados em livro e sob a forma de artigos num dos números de 2010 da Revista Brasileira de Política e Administração da Educação (RBPAE), num total de três artigos, cada qual abordando um dos subconjuntos das fontes documentais. Pontuamos a seguir destaques do artigo publicado na RBPAE que trata do exame de teses e dissertações.

Martins e Silva (2010) analisaram 406 teses e dissertações concluídas entre 2000 e 2008. De modo pontual, sintetizamos a seguir os resultados apresentados pelos autores.

- Distribuição entre dissertações e teses: $86 \%$ e 14\%, respectivamente.

- Sudeste com a maior incidência (51\%) e no outro extremo o norte (3\%); entre os dois, uma proporção aproximada (variando em torno de 15\%) entre as demais regiões. A distribuição de dissertações entre as regiões segue mais ou menos a distribuição do total, na verdade a determina, dada a predominância de dissertações na produção total. Já as teses foram produzidas numa proporção de $73 \%$ no sudeste, $25 \%$ no nordeste, $2 \%$ no centro-oeste e nenhuma tese sobre as temáticas foi localizada nas regiões sul e norte.

- No que concerne à distribuição entre as dependências administrativas pública e privada, $69 \%$ das dissertações e teses foram produzidas em instituições públicas e 31\% em instituições particulares.

- Foram registradas 12 instituições com mais de 10 trabalhos (concentraram 45\% da produção), nenhuma delas é da região sul do Brasil. Chama atenção a concentração em instituições de São Paulo: somando PUC/SP, USP, UNESP, Unicamp e UFSCar, foram registrados 90 trabalhos.

- As produções discentes foram agrupadas em categorias: (1) relações e práticas escolares (43\% do total); (2) programas e projetos governamentais e não governamentais (40\% do total); (3) espaços e canais de participação intraescolar (15\% do total); (4) teorias e conceitos (3\%).

- Os autores assinalam que não há perspectivas teórico-metodológicas predominantes nos estudos e, sim, distintas abordagens. Embora a diversidade de abordagens, predominam os estudos de caráter qualitativo, principalmente os estudos de caso e diversas técnicas de coleta de dados sem explicitação dos cruzamentos realizados para fins de análise. Argumentam que as características dos programas de pós graduação são elementos que demarcam as fragilidades e lacunas detectadas nos estudos: predominam dissertações de mestrado realizadas em pouco tempo, parte sem financiamento e apoios. Isso não favorece o desenvolvimento de subprojetos integrados a investigações de maior escopo e implementadas por grupos de pesquisa.

5 Foram tomados apenas os trabalhos do GT 5 - Estado e Política Educacional. 
Barreto (2009) tratou de abordagens presentes em estudos acadêmicos sobre políticas educacionais no campo da educação no Brasil. Segundo a autora, sua referência primeira foram trabalhos apresentados no Grupo de Trabalho 5 da Anped - Estado e Política Educacional -, mas vários outros estudos sobre a temática foram considerados.

A autora adjetiva de fragmentada a produção na área; ela não chega a apresentar algum panorama dessa fragmentação, restringe-se a afirmá-la. Mais do que isso, Barreto cunha de fragmentada tanto a produção acadêmica sobre políticas educacionais, quanto, de resto, outras temáticas no campo da educação no Brasil o que, segundo ela, é constatado em estados da arte e outros levantamentos periodicamente realizados. Predominam, segundo sua avaliação, os estudos de caso e é raro encontrar pesquisas com amostras representativas e que possam dar conta da abrangência de processos e efeitos dos fenômenos. Os estudos de caso e abordagens microssociais elucidam aspectos das políticas, mas não têm fôlego para tratar de dimensões mais abrangentes, tais como desenho institucional, cobertura e financiamento das políticas, que seriam "cruciais para entender os condicionantes, o modo como funcionam e os resultados a que chegam" (BARRETO, 2009, p. 2).

Elba Barreto entende que os levantamentos da produção acadêmica que têm sido realizados são importantes para sistematizar resultados de pesquisa, ou para apontar lacunas e tendências, contudo, esses não podem substituir a realização dos estudos em si, quer dizer, estudos sobre políticas com análises mais compreensivas e que auxiliem na própria constituição do campo. Segundo a autora, a pulverização da produção limita a possibilidade de que essa produção seja tomada como referência para as macrodecisões sobre a política educacional.

Destaca o predomínio da tradição marxista de análise. Segundo ela, alguns trabalhos utilizam bem esses referenciais, mas um número significativo recorre a pressupostos muito genéricos e busca validá-los por meio de algumas evidências empíricas, sem exame aprofundado do contexto em que as políticas são formuladas e/ou implementadas. Em muitos trabalhos permanecem análises deterministas, com aplicação linear de esquemas interpretativos abstratos a políticas concretas, a despeito das mudanças paradigmáticas que ocorreram nos últimos anos.

Cabe destacar que a autora, no artigo aqui referido, faz sugestões para estudos de política educacional, basicamente com referências afeitas a estudos do tipo análise de políticas públicas e com a menção a aspectos mais gerais e a singularidades de estudos sobre formulação, implementação ou avaliação.

Os estudos acima resenhados, já dissemos, auxiliaram nas escolhas de nosso levantamento da produção discente nos programas de pós-graduação em educação da região sul. Alguns dos resultados do estudo são apresentados na próxima seção.

\section{Gestão e políticas educacionais nas teses e dissertações dos programas de pós-graduação em educação da região Sul}

Em 2010, havia na região sul do Brasil 28 programas de pós-graduação em educação (PPG-Edu); a distribuição entre os estados e conforme o tipo de curso oferecido encontra-se na Tabela 1.

Tabela 1 - Número de programas de pós-graduação em educação da região Sul, por tipo de cursos oferecidos e por estado - 2010

\begin{tabular}{|c|c|c|c|}
\hline Estado/ Tipo de Curso & Mestrado & Mestrado e Doutorado & Total \\
\hline Paraná & 2 & 5 & 7 \\
\hline Rio Grande do Sul & 7 & 5 & 12 \\
\hline Santa Catarina & 8 & 1 & 9 \\
\hline Total & 17 & 11 & 28 \\
\hline
\end{tabular}

Fonte: Capes 
O primeiro procedimento do levantamento foi separar as universidades do sul do país que possuíssem teses e dissertações defendidas junto a programas de pós-graduação, organizando-as por estados. Os dados foram coletados no site da Coordenação de Aperfeiçoamento de Pessoal de Nível Superior (Capes). Pelo modo como é possível fazer essa busca, esse procedimento foi bastante trabalhoso. Por exemplo, foi necessário, para cada conjunto de palavras-chave, fazer a busca por instituição e, de cada instituição, por ano e por nível (mestrado e/ou doutorado). No banco de teses e dissertações da Capes foram sendo identificadas, em cada universidade selecionada, as produções de teses e dissertações entre os anos de 2000 a 2010 que tratassem de temáticas incluídas em política e gestão da educação básica.

A seleção foi feita com a leitura das informações disponíveis no Banco de Teses/ Capes, onde se tem acesso a informações sintéticas de cada produção discente: ano, instituição, orientador, membros da banca, resumo e palavras-chave. Para fazer o filtro da pesquisa foram sendo sucessivamente preenchidos os campos: assunto; instituição; nível (mestrado ou doutorado) e ano base. No campo assunto a palavra chave padrão foi Educação (normalmente acompanhada de uma segunda palavra que auxiliava a fazer um filtro mais preciso). No entanto, de acordo com o volume de produção de cada universidade e com o ano pesquisado, houve variações nessas palavras. As variações foram: gestão, política, administração, diretrizes, projetos, direito.

Nas universidades que possuíam menor produção de teses e/ou dissertações, só a palavra educação era utilizada para a pesquisa. Nas universidades com maior produção, a cada nova pesquisa de cada ano da mesma universidade era usada sempre a palavra educação seguida de cada palavra auxiliar. Isso com exceção da palavra administração, utilizada apenas nos anos de 2000 a 2005, pois mais recentemente o termo administração foi sendo substituído pelo termo gestão.

Cabe fazer um esclarecimento importante. Foram consideradas apenas as dissertações e teses que tratavam diretamente da educação básica. Em virtude da quantidade de estudos, nessa fase do levantamento não foram levados em conta os aqueles sobre os seguintes temas: formação inicial de professores (análises sobre características e concepções de cursos de formação inicial); ensino técnico, a não ser quando o resumo explicitava suas relações com a formação geral de nível médio; estudos cujos resumos indicavam um foco em práticas ou concepções pedagógicas, mesmo que o título, as palavras-chave e alguns conteúdos mencionassem política educacional.

Cabe mais uma ressalva importante: possivelmente há dissertações e teses que ficaram fora do levantamento em virtude de não terem sido localizadas com os filtros de busca aplicados. Outra precisão diz respeito aos conteúdos dos resumos: há trabalhos que entraram no banco de dados num primeiro momento, em virtude da incidência dos termos de busca no título, nas palavras-chave ou nos resumos, e que depois foram excluídos pelo fato de não haver indicações consistentes de que se tratava de estudo sobre política educacional ou sobre gestão da educação; talvez o fossem, mas nesse caso houve deficiências no resumo, ao que se somou nossa impossibilidade de buscar os trabalhos completos.

Teses e dissertações sobre política e gestão da educação em números

Agrupamos as quantidades de teses e dissertações em alguns intervalos temporais, o que está registrado na Tabela 2, a seguir. No anexo encontra-se a tabela completa, por ano e por instituição. 
Tabela 2 - Produções discentes sobre temas de política e gestão da Educação Básica, por estado e por intervalos de anos - programas de pós-graduação em Educação da região sul - 2000-2010

\begin{tabular}{|c|c|c|c|c|c|c|c|c|c|}
\hline \multirow{2}{*}{ Total } & \multicolumn{2}{|c|}{$2000-2002$} & \multicolumn{2}{|c|}{ 2003-2006 } & \multicolumn{2}{|c|}{ 2007-2010 } & \multirow[b]{2}{*}{$\mathrm{M}$} & \multirow[b]{2}{*}{$\mathrm{D}$} & \multirow[b]{2}{*}{$M+D$} \\
\hline & $\mathrm{M}$ & $\mathrm{D}$ & $\mathrm{M}$ & $\mathrm{D}$ & $M$ & $D$ & & & \\
\hline Paraná & 16 & & 63 & & 99 & 2 & 178 & 2 & 180 \\
\hline Santa Catarina & 16 & 1 & 28 & 2 & 52 & 6 & 96 & 9 & 105 \\
\hline Rio Grande do Sul & 28 & 3 & 58 & 7 & 70 & 18 & 156 & 28 & 182 \\
\hline Total & 60 & 4 & 149 & 9 & 221 & 26 & 430 & 39 & 469 \\
\hline
\end{tabular}

Fonte: Banco de Teses da Capes

Nota: $\mathrm{M}$ - mestrado; D - doutorado

Uma primeira constatação é o crescente aumento da produção sobre a temática no período. No nível de mestrado, foram 60 trabalhos no primeiro intervalo, 149 no segundo e 221 no terceiro; no nível de doutorado, quatro no período 2000-2002, nove no período seguinte e 26 no período 2007-2010. Infelizmente não conseguimos a informação do quantitativo total de teses e dissertações defendidas nos PPG-Edu da região para verificar a proporção dos estudos em política e gestão e a sua evolução vis-à-vis o conjunto de estudos. Deste modo, apenas podemos apontar o crescimento no total e em cada um dos estados.

No doutorado (Tabela 3), foram encontradas teses sobre política e gestão da educação nas instituições que há mais tempo possuem cursos nesse nível: Universidade Federal do Paraná (UFPR), Universidade Federal de Santa Catarina (UFSC), Pontifícia Universidade Católica do Rio Grande do Sul (PUC/RS), Universidade do Vale do Rio dos Sinos (Unisinos) e Universidade Federal do Rio Grande do Sul (UFRGS).

Tabela 3 - Número de teses de doutorado sobre temas de política e gestão da Educação Básica, por instituição e por ano - PPG-Edu da região Sul - 2000-2010

\begin{tabular}{|c|c|c|c|c|c|c|c|c|c|c|c|c|}
\hline Instituição/ Ano & 2000 & 2001 & 2002 & 2003 & 2004 & 2005 & 2006 & 2007 & 2008 & 2009 & 2010 & TOTAL \\
\hline UFPR & & & & & & & & & & 1 & 1 & 2 \\
\hline UFSC & & & 1 & & 1 & & 1 & & 4 & & 2 & 9 \\
\hline PUC/RS & & & & & & 2 & & & & 1 & & 3 \\
\hline UNISINOS & & & & 1 & 2 & & & 1 & & & 2 & 6 \\
\hline UFRGS & 1 & 1 & 1 & 1 & & 1 & & 1 & 3 & 2 & 8 & 19 \\
\hline TOTAL & 1 & 1 & 2 & 2 & 3 & 3 & 1 & 2 & 7 & 4 & 13 & 39 \\
\hline
\end{tabular}

Fonte: Banco de Teses da Capes

No nível do mestrado (Tabela A1, no anexo) foram encontradas dissertações sobre política educacional e/ou gestão educacional em 26 instituições: sete instituições do Paraná; oito de Santa Catarina e 11 do Rio Grande do Sul. Em todos os estados, a maior produção foi encontrada nas universidades federais mais antigas - UFPR, UFSC e UFRGS. Nos abstemos de fazer comentários que digam respeito à distribuição entre instituições ou à distribuição temporal, pois para tal seriam necessárias informações sobre o tempo de funcionamento dos programas, o total de dissertações defendidas nesses anos e as linhas de pesquisa existentes.

Temáticas e territórios pesquisados em política e gestão da educação

$\mathrm{Na}$ Tabela 4 encontra-se a quantidade de trabalhos dos PPG-Edu do RS e de SC distribuída por grandes temas (categorias temáticas), o que foi combinado com uma distribuição de acordo com o território que foi objeto de atenção nas teses e dissertações. 
Tabela 4 - Número de dissertações de mestrado (M) e teses de doutorado (D) sobre temas de política e gestão da Educação Básica, por categorias temáticas e territórios de referência - PPG-Edu Rio Grande do Sul, Santa Catarina e Paraná - 2000-2010

\begin{tabular}{|c|c|c|c|c|}
\hline \multicolumn{2}{|c|}{ Nível/ Tema e Território } & M & D & $M+D$ \\
\hline \multicolumn{5}{|c|}{ Políticas públicas } \\
\hline \multirow{6}{*}{ Territórios } & Escola & 26 & 2 & 28 \\
\hline & Município & 85 & 3 & 88 \\
\hline & Estado & 69 & 6 & 75 \\
\hline & Nacional & 39 & 11 & 50 \\
\hline & Nacionais & 5 & 2 & 7 \\
\hline & Subtotal & 224 & 24 & 248 \\
\hline \multicolumn{5}{|c|}{ Gestão de sistemas/rede } \\
\hline \multirow{5}{*}{ Territórios } & Município & 32 & 2 & 34 \\
\hline & Estado & 13 & 2 & 15 \\
\hline & Nacional & 3 & 0 & 3 \\
\hline & Nacionais & 0 & 0 & 0 \\
\hline & Subtotal & 48 & 4 & 52 \\
\hline \multicolumn{5}{|c|}{ Gestão de escolas } \\
\hline \multirow{6}{*}{ Territórios } & Escola & 43 & 0 & 43 \\
\hline & Município & 20 & 0 & 20 \\
\hline & Estado & 5 & 1 & 6 \\
\hline & Nacional & 3 & 1 & 4 \\
\hline & Nacionais & 1 & 0 & 1 \\
\hline & Subtotal & 72 & 2 & 74 \\
\hline \multicolumn{5}{|c|}{ Legislação e normas educacionais } \\
\hline \multirow{6}{*}{ Territórios } & Escola & 6 & 0 & 6 \\
\hline & Município & 4 & 1 & 5 \\
\hline & Estado & 1 & 0 & 1 \\
\hline & Nacional & 6 & 0 & 6 \\
\hline & Nacionais & 2 & 0 & 2 \\
\hline & Subtotal & 19 & 1 & 20 \\
\hline \multicolumn{5}{|c|}{ Políticas públicas } \\
\hline \multirow{6}{*}{ Territórios } & Escola & 0 & 0 & 0 \\
\hline & Município & 6 & 0 & 6 \\
\hline & Estado & 4 & 0 & 4 \\
\hline & Nacional & 6 & 2 & 8 \\
\hline & Nacionais & 1 & 0 & 1 \\
\hline & Subtotal & 17 & 2 & 19 \\
\hline \multicolumn{2}{|c|}{ Total } & 380 & 33 & 413 \\
\hline
\end{tabular}

Fonte: Banco de Teses da Capes 
A distribuição por ano, de cada estado, encontra-se no anexo, ao final desse artigo. Apresentamos aqui apenas informações referentes aos trabalhos que puderam ser inseridos nas categorias temáticas e territórios que constam na Tabela 4, deixamos de fora os trabalhos que foram encaixados nas situações outros, tanto em temas quanto em territórios, por isso há diferença entre os números das tabelas 2 e 3 e os da Tabela 4.

As categorias temáticas foram estabelecidas com base na leitura dos resumos e com base em categorias estabelecidas no estado da arte que se encontra em Wittmann e Gracindo (1999), já referido.

Dos 413 trabalhos considerados, a distribuição percentual entre as temáticas foi a seguinte: $60 \%$ em políticas públicas; $18 \%$ em gestão de escola(s), 13\% em gestão de sistemas de ensino ou redes de ensino; $5 \%$ em direito à educação e 5\% em legislação e normas educacionais.

Diferentemente do estudo de Wittmann e Gracindo (1999), não estabelecemos a categoria profissionais da educação, a qual, nele, foi a que teve maior incidência de textos. Mesmo assim, parte das dissertações e teses de nosso levantamento trata de políticas públicas de formação continuada de profissionais do magistério, o que foi considerado no levantamento. A incidência de trabalhos em políticas públicas é significativa. Chama a atenção a diferença em relação à segunda categoria, gestão de escola(s). Se considerarmos apenas as teses de doutorado, 73\% tematizaram política(s) pública(s), quatro focaram gestão de sistema ou rede de ensino e apenas duas foram incluídas na categoria gestão de escola.

Direito à educação, assim como legislação e normas educacionais, aparecem como objeto central de um número bastante reduzido de trabalhos; essas temáticas estão presentes na maior parte dos estudos, mas não como objeto de pesquisa e sim como elementos contextuais ou normativos para dar suporte às análises sobre políticas e gestão da educação. É comum os trabalhos sobre políticas públicas ou gestão de redes de ensino e escolas confrontarem direito ou direitos à educação e legislação e normas com as práticas das políticas e da gestão, em geral para assinalar a distância existente entre os dois âmbitos.

No que concerne aos territórios, a distribuição, considerando todas as categorias temáticas, é a seguinte: 37\% município(s), 19\% escola(s), 24\% estado(s) (unidade da federação), 17\%, nacional e 3\% nacionais. A categoria estado diz respeito a unidade da federação; a categoria nacional engloba estudos cujo olhar recai no território nacional brasileiro, ou seja, sem foco em escola, município ou estado; na categoria nacionais foram inseridos estudos que tratam do Brasil e mais algum(ns) país(es).

Na temática políticas públicas, 85 dissertações e três teses focaram o território município, muitas delas trabalhando com a implementação de políticas em redes municipais. Podemos cogitar que essa incidência se deve, principalmente, aos seguintes fatores: o peso e o papel das redes municipais de ensino, que se ampliou com a municipalização da educação infantil e do ensino fundamental e com a criação de sistemas municipais de ensino ou fortalecimento institucional das redes municipais; o crescimento e diversificação de políticas propostas pelo governo federal, de execução intergovernamental (União e município). Nas teses de doutorado, se destaca o foco no território nacional (11 teses), principalmente com pesquisas que discutem a formulação ou referenciais de política ou de políticas da União.

\section{O que caracterizaria a pesquisa em política e gestão da educação?}

$\mathrm{Na}$ seção desse texto denominada Estudos e reflexões sobre a produção acadêmica em gestão e políticas educacionais, fizemos referência a um artigo Martins e Silva (2010), que contém resultados de um estado da arte de dissertações e teses sobre processos de gestão, autonomia escolar e órgãos colegiados. Nesse artigo, os autores fazem uma avaliação sobre estudos que focaram gestão e autonomia escolar. Nos inspiramos nessa avaliação para a escrita do próximo parágrafo, mas referindo-nos às teses e dissertações que examinamos, referentes a políticas e gestão da educação em geral, e não apenas a unidades escolares. 
É muito comum os estudos docentes colocarem o acento nas distâncias entre o que é proposto em diretrizes da legislação ou de políticas governamentais e o que ocorre nas práticas das redes escolares e nas escolas. Encontramse, em muitos trabalhos, perspectivas demasiadamente amplas e essas são tomadas como determinações para explicar qualquer contexto da educação escolar, deixando de ser dada a devida atenção a especificidades institucionais e políticas de sistemas, redes e escolas, bem como mediações que operam na recontextualização de prescrições legais ou de prescrições de políticas, seja na perspectiva temporal, seja na perspectiva de condições político-institucionais e de posicionamento dos atores envolvidos. A consideração mais generalizada de contextos específicos na análise da política e da gestão é elemento metodológico que poderia qualificar os estudos discentes.

Um detalhamento que não realizamos ainda diz respeito às etapas, modalidades, ou tópicos específicos por exemplo, profissionais da educação, financiamento da educação - que são objeto das pesquisas. Esse é um aspecto que valeria a pena acrescentar ao levantamento, pois indicaria mais uma tendência que poderia compor o quadro da produção na área.

Vimos que o número de estudos é significativo e foi crescendo ao longo dos anos. Mesmo sem poder apontar a proporção que representa no total de teses e dissertações defendidas nos programas, podemos cogitar que essa tenha sido crescente. Por exemplo, um parâmetro pode ser oferecido pelo número de trabalhos que têm sido submetidos às reuniões anuais da Anped nos últimos anos. Em 2011, os trabalhos submetidos ao Grupo de Trabalho (GT) Estado e Política Educacional foram mais de 60, número que ficou atrás apenas do GT Formação de Professores. Em 2012, foram submetidos 62 trabalhos ao GT Estado e Política Educacional, o mesmo número do GT Formação de Professores; esses foram os grupos de trabalho com maior número de submissões. Vimos também uma maior incidência de estudos em políticas públicas e em gestão de escolas, com o território município com maior volume de pesquisas.

O levantamento realizado nos indica que a especificidade da pesquisa em política e gestão da educação merece atenção. Se pensarmos apenas em três dimensões presentes nos estudos - temáticas, territórios e etapas/ modalidades da educação ou tópicos específicos - encontraremos grande diversidade nas pesquisas. Junte-se a isso mais uma característica que não pudemos aqui quantificar, mas que a leitura dos trabalhos faz saltar aos olhos: a predominância de estudos de caso em escola(s) ou rede(s) de ensino. O tipo mais comum de pesquisa é: política X, referente à etapa ou modalidade X da educação básica, na escola, estado ou município X. Parece-nos que se vão agregando ou construindo conhecimentos científicos que são relevantes do ponto de vista das etapas, modalidades ou tópicos específicos da educação, bem como das possibilidades e limites de cada política ou prática de gestão estudada e, ainda, das especificidades dos territórios. Enfim, olhando por esse ângulo, os aportes de nossas pesquisas, mesmo na ocorrência da fragmentação, são política e academicamente relevantes.

De outra parte, do ponto de vista da produção do conhecimento, talvez valha a pena pensar no que é que caracteriza a inscrição de estudos acadêmicos em Política e Gestão da Educação. Somente a construção de macro e meso contextos não é suficiente para (re)ligar produções que combinam determinada política ou situação de gestão num dado território. Pesquisas sobre a política de educação infantil no município X; ou sobre a política de formação de professores do MEC; ou sobre a gestão da política de educação especial no estado X: são estudos, respectivamente, sobre a educação infantil, a formação de professores e a educação especial. São estudos que poderiam resultar, respectivamente, em trabalhos a serem submetidos aos GTs de educação infantil, de formação de professores e de educação especial da Anped ou dos encontros regionais da Anped, por exemplo. O que caracteriza ou caracterizaria esses estudos como também vinculados à política e/ou à gestão da educação?

Dadas essas considerações, a pergunta que fazemos é: guardadas as particularidades das etapas, modalidades e tópicos específicos da educação, há marcos teórico-metodológicos que poderiam ser pensados como constituintes de uma singularidade da pesquisa em Política e Gestão da Educação? E mais: se a pulverização da produção na área limita a possibilidade de que essa produção seja tomada como referência para as macrodecisões sobre a política educacional, a constituição dessa singularidade contribuiria para minimizar essa limitação? 


\section{Referências Bibliográficas}

AZEVEDO, Janete M. L. de; AGUIAR, Marcia Ângela da S. A produção do conhecimento sobre política educacional no Brasil: um olhar a partir da Anped. Educação \& Sociedade, Campinas, v. 22, n. 77, p. 49-70, dez. 2001.

BARRETO, Elba. Perspectivas teóricas e metodológicas da pesquisa em política educacional na atualidade. Estudos em avaliação educacional, n. 44, 2009.

CAMPOS, Maria Malta. Para que serve a pesquisa em educação? Cadernos de Pesquisa, v. 39, n. 136, p. 269-283, jan./abr. 2009.

CASTRO, Marta Luz S. ; WERLE, Flávia O. C. Estado do conhecimento em administração da educação: uma análise dos artigos publicados em periódicos nacionais 1982-2000. Ensaio: aval. pol. publ. educ., Rio de Janeiro,v. 12, n. 45, p. 1045-64, out./dez. 2004.

MAIA, Graziela Z. As publicações da Anpae e a trajetória do conhecimento em administração da educação no Brasil. Revista Brasileira de Política e Administração da Educação, Porto Alegre, v. 24, n. 1, p. 31-50, jan./abr. 2008.

MAINARDES, Jefferson; FERREIRA, Márcia dos S.; TELLO, César. Análise de políticas: fundamentos e principais debates teórico-metodológicos. In: BALL, Stephen e MAINARDES, Jefferson (Orgs.). Políticas educacionais: questões e dilemas. São Paulo: Cortez Editora, p. 143-172, 2011.

MARTINS, Angela Maria. A pesquisa na área de política e gestão da educação básica: aspectos teóricos e metodológicos. Educação \& Realidade, Porto Alegre, v. 36, n. 2, p. 379-393, maio/ago. 2011.

MARTINS, Angela Maria; SILVA, Vandré Gomes da. Gestão escolar, autonomia escolar e órgãos colegiados: a produção de teses e dissertações (2000-2008). Revista Brasileira de Política e Administração da Educação - RBPAE, v. 26, n. 3, p. 421-440, set./dez. 2010.

OLIVEIRA, Cleiton de; LOPES, Valéria Virginia. Autonomia, gestão escolar e órgãos colegiados: a produção de artigos em periódicos científicos (2000-2008). Revista Brasileira de Política e Administração da Educação - RBPAE, v. 26, n. 3, p. 461-476, set./dez. 2010.

PAZETO, Antonio Elizzio e WITTMANN, Lauro Carlos. Gestão da escola. In: WITTMANN, Lauro Carlos; GRACINDO, Regina Vinhaes. O estado da arte em política e gestão da educação no Brasil: 1991 a 1997. Brasília: Anpae, p. 203-215, 1999.

PEREIRA, Gilson R. de M.; ANDRADE, Maria da Conceição L. de. A construção da administração da educação na RBPAE (1983-1996). Educação \& Sociedade, Campinas, v. 26, n. 93, 1393-1411, set./dez. 2005.

SANTOS, Ana Lúcia F. dos; AZEVEDO, Janete M. L. de. A pós-graduação no Brasil, a pesquisa em educação e os estudos sobre a política educacional: os contornos da constituição de um campo acadêmico. Revista Brasileira de Educação, v. 14, n. 42, p. 534-605, set./dez. 2005.

SOUZA, Ângelo R. de. A produção do conhecimento e o ensino da gestão educacional no Brasil. Revista Brasileira de Política e Administração da Educação, Porto Alegre, v. 24, n. 1, p. 51-60, jan./abr. 2008.

SOUZA, Ângelo R. de. Os caminhos da produção científica sobre a educação escolar no Brasil. Revista Brasileira de Política e Administração da Educação, Porto Alegre, v. 22, n. 1, p. 13-39, jan./jun. 2006.

SOUZA, Donaldo Bello de. Anais dos eventos da Anped e da Anpae (2000-2008) e o estado da temática gestão, autonomia escolar e órgãos colegiados. Revista Brasileira de Política e Administração da Educação - RBPAE, v. 26, n. 3, p. 441-459, set./dez. 2010.

WITTMANN, Lauro Carlos; GRACINDO, Regina Vinhaes. O estado da arte em política e gestão da educação no Brasil: 1991 a 1997. Brasília: Anpae, 1999. 


\section{Anexo}

Tabela A1 - Número de dissertações de mestrado, por instituição e por ano - PPG-Edu da região Sul - 2000-2010

\begin{tabular}{|c|c|c|c|c|c|c|c|c|c|c|c|c|}
\hline Ano/Instituição & 2000 & 2001 & 2002 & 2003 & 2004 & 2005 & 2006 & 2007 & 2008 & 2009 & 2010 & Total \\
\hline \multicolumn{13}{|l|}{ Paraná } \\
\hline PUC/PR & & & & 1 & 2 & & 4 & 5 & 1 & 3 & 5 & 21 \\
\hline UEM & & 1 & 2 & 3 & 3 & 2 & 6 & 3 & 2 & 3 & 4 & 29 \\
\hline UEPG & & 1 & 5 & 2 & 4 & 3 & 1 & 2 & 6 & 3 & 1 & 28 \\
\hline UNIOESTE & & & & & & & & & & 3 & 3 & 6 \\
\hline UEL & & & & & 1 & 1 & 1 & & 4 & 4 & 3 & 14 \\
\hline UFPR & 1 & 3 & & 6 & 4 & 4 & 5 & 6 & 6 & 5 & 8 & 48 \\
\hline UTP & & 1 & 2 & & 3 & 2 & 5 & 5 & 4 & 2 & 8 & 32 \\
\hline Subtotal & 1 & 6 & 9 & 12 & 17 & 12 & 22 & 21 & 23 & 23 & 32 & 178 \\
\hline \multicolumn{13}{|l|}{ Santa Catarina } \\
\hline UNIVILLE & & & & & & & & 1 & & & & 1 \\
\hline UDESC & & & & & & & 1 & & & & 2 & 3 \\
\hline UNESC & & & & & & & & 1 & & & & 1 \\
\hline UNOESC & & & & & & & & & 1 & 6 & 4 & 11 \\
\hline UNISUL & & & & & & & & 1 & & & & 1 \\
\hline UNIVALI & & & & 3 & 1 & 1 & 3 & 1 & 2 & 3 & 1 & 15 \\
\hline UFSC & 4 & 4 & 6 & 2 & 2 & 4 & 5 & 1 & 8 & 2 & 7 & 45 \\
\hline FURB & & & 2 & 2 & 2 & 1 & 1 & 2 & 3 & 1 & 5 & 19 \\
\hline Subtotal & 4 & 4 & 8 & 7 & 5 & 6 & 10 & 7 & 14 & 12 & 19 & 96 \\
\hline \multicolumn{13}{|l|}{ Rio Grande do Sul } \\
\hline UNILASALLE & & & & & & & & & & 2 & 1 & 3 \\
\hline PUC/RS & 1 & 3 & & 1 & 1 & 1 & & 1 & 1 & 1 & 2 & 12 \\
\hline UCS & & & & & & & & & & 1 & & 1 \\
\hline UPF & & & & 4 & 1 & 1 & 2 & 4 & 5 & 5 & 4 & 26 \\
\hline UNISC & & 1 & & 1 & & 1 & 1 & 1 & & 1 & 1 & 7 \\
\hline UNISINOS & 2 & & 1 & 1 & 3 & & 5 & 3 & 2 & 2 & 2 & 21 \\
\hline UFPEL & & 2 & 3 & & 1 & 1 & 1 & 1 & 1 & 1 & 2 & 13 \\
\hline UFSM & & & 1 & 2 & 1 & & 2 & & & & & 6 \\
\hline FURG & & 1 & & & 3 & 1 & & & 2 & & 1 & 8 \\
\hline UFRGS & 2 & 2 & 9 & 3 & 2 & 9 & 6 & 9 & 4 & 6 & 1 & 53 \\
\hline ULBRA & & & & & & 2 & 1 & & 1 & 1 & 1 & 6 \\
\hline Subtotal & 5 & 9 & 14 & 12 & 12 & 16 & 18 & 19 & 16 & 20 & 15 & 156 \\
\hline Total & 10 & 19 & 31 & 31 & 34 & 34 & 50 & 47 & 53 & 55 & 66 & 430 \\
\hline
\end{tabular}

Fonte: Banco de Teses da Capes 
Tabela A2 - Número de dissertações de mestrado (M) e teses de doutorado (D) sobre temas de política e gestão da Educação Básica, por categorias temáticas e territórios de referência, por ano - PPG-Edu Paraná - 2000-2010

\begin{tabular}{|c|c|c|c|c|c|c|c|c|c|c|c|c|c|c|c|c|c|}
\hline \multirow{2}{*}{\multicolumn{2}{|c|}{$\begin{array}{c}\text { Ano e Nível/ } \\
\text { Tema e Território }\end{array}$}} & \multirow{2}{*}{$\frac{2000}{M}$} & \multirow{2}{*}{2001} & \multirow{2}{*}{$\begin{array}{c}2002 \\
M\end{array}$} & \multirow{2}{*}{$\begin{array}{c}2003 \\
M\end{array}$} & \multirow{2}{*}{$\begin{array}{c}2004 \\
M\end{array}$} & \multirow{2}{*}{$\begin{array}{c}2005 \\
M\end{array}$} & \multirow{2}{*}{$\begin{array}{c}2006 \\
M\end{array}$} & \multirow{2}{*}{\begin{tabular}{|c|}
2007 \\
$M$
\end{tabular}} & \multirow{2}{*}{\begin{tabular}{|c|}
2008 \\
$M$
\end{tabular}} & \multicolumn{2}{|c|}{2009} & \multicolumn{2}{|c|}{2010} & \multicolumn{3}{|c|}{ Totais } \\
\hline & & & & & & & & & & & $\mathrm{M}$ & D & M & $\mathrm{D}$ & M & D & $M+D$ \\
\hline \multicolumn{18}{|c|}{ Políticas públicas } \\
\hline \multirow{6}{*}{ : } & Escola & & & & & 1 & & & & & & & & & 1 & & 1 \\
\hline & Município & & 2 & & 3 & 2 & 4 & 7 & 4 & 6 & 5 & & 6 & & 39 & & 39 \\
\hline & Estado & & 3 & 1 & 4 & 4 & 2 & 1 & 6 & 2 & 5 & 1 & 7 & & 39 & 1 & 40 \\
\hline & Nacional & & & 2 & 2 & 1 & 4 & 3 & & 1 & 3 & & 4 & & 20 & & 20 \\
\hline & Nacionais & & & & & & & & & & 1 & & 1 & & 2 & & 2 \\
\hline & Subtotal & & 5 & 3 & 9 & 8 & 10 & 11 & 10 & 9 & 14 & 1 & 18 & 0 & 101 & 1 & 102 \\
\hline \multicolumn{2}{|c|}{$\begin{array}{c}\text { Gestão de } \\
\text { sistemas/rede }\end{array}$} & & & & & & & & & & & & & & & & \\
\hline \multirow{5}{*}{ : } & Município & & & & 1 & & & 2 & 1 & 2 & 2 & & 3 & & 11 & & 11 \\
\hline & Estado & & & & & 1 & & 2 & 1 & 1 & 2 & & & & 7 & & 7 \\
\hline & Nacional & & & & 1 & & & & 1 & 1 & & & & & 3 & & 3 \\
\hline & Nacionais & & & & & & & & & & & & & & & & \\
\hline & Subtotal & & & & 2 & 1 & & 4 & 3 & 4 & 4 & & 3 & & 21 & & 21 \\
\hline \multicolumn{18}{|c|}{ Gestão de escolas } \\
\hline \multirow{6}{*}{ 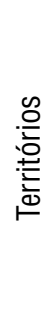 } & Escola & & & 2 & & 4 & & 1 & 2 & 2 & & & 1 & & 12 & & 12 \\
\hline & Município & & & 2 & & 1 & & & 1 & & & & 2 & & 6 & & 6 \\
\hline & Estado & 1 & & & & & 1 & & & & & & & & 2 & & 2 \\
\hline & Nacional & & 1 & & & & & & & 1 & & & & 1 & 2 & 1 & 3 \\
\hline & Nacionais & & & & & & & & & & & & & & & & \\
\hline & Subtotal & 1 & 1 & 4 & & 5 & 1 & 1 & 3 & 3 & & & 3 & 1 & 22 & 1 & 23 \\
\hline \multicolumn{2}{|c|}{$\begin{array}{l}\text { Direito à } \\
\text { educação }\end{array}$} & & & & & & & & & & & & & & & & \\
\hline \multirow{6}{*}{ 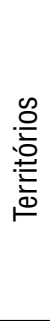 } & Escola & & & & & & & & & & & & & & & & \\
\hline & Município & & & & & & & & & & 1 & & & & 1 & & 1 \\
\hline & Estado & & & & & & & & & 1 & & & & & 1 & & 1 \\
\hline & Nacional & & & & & & & 1 & & 2 & & & & & 3 & & 3 \\
\hline & Nacionais & & & & & & & & & & & & & & & & \\
\hline & Subtotal & & & & & & & 1 & & 3 & 1 & & & & 5 & & 5 \\
\hline \multicolumn{2}{|c|}{$\begin{array}{l}\text { Legislação } \\
\text { e normas } \\
\text { educacionais }\end{array}$} & & & & & & & & & & & & & & & & \\
\hline & Escola & & & & & & & & & & & & & & & & \\
\hline & Município & & & & & & 1 & & 1 & & & & & & 2 & & 2 \\
\hline 음 & Estado & & & & & & & & 1 & & & & 2 & & 3 & & 3 \\
\hline 产 & Nacional & & & & 1 & 2 & & & & & & & & & 3 & & 3 \\
\hline & Nacionais & & & & & & & & 1 & & & & & & 1 & & 1 \\
\hline & Subtotal & & & & 1 & 2 & 1 & & 3 & & & & 2 & & 9 & & 9 \\
\hline & Total & & & & & & & & & & & & & & 158 & 2 & 160 \\
\hline
\end{tabular}


Tabela A3 - Número de dissertações de mestrado (M) e teses de doutorado (D) sobre temas de política e gestão da Educação Básica, por categorias temáticas e territórios de referência, por ano - PPG-Edu Rio Grande do Sul - 2000-2010

\begin{tabular}{|c|c|c|c|c|c|c|c|c|c|c|c|c|c|c|c|c|c|c|c|c|c|c|c|c|c|c|}
\hline \multirow{2}{*}{\multicolumn{2}{|c|}{$\begin{array}{c}\text { Ano e Nível/ } \\
\text { Tema e Território }\end{array}$}} & \multicolumn{2}{|c|}{2000} & \multicolumn{2}{|c|}{2001} & \multicolumn{2}{|c|}{2002} & \multicolumn{2}{|c|}{2003} & \multicolumn{2}{|c|}{2004} & \multicolumn{2}{|c|}{2005} & \multicolumn{2}{|c|}{2006} & \multicolumn{2}{|c|}{2007} & \multicolumn{2}{|c|}{2008} & \multicolumn{2}{|c|}{2009} & \multicolumn{2}{|c|}{2010} & \multicolumn{3}{|c|}{ Totais } \\
\hline & & $\mathrm{M}$ & $D$ & $M$ & $D$ & $\mathrm{M}$ & $D$ & $M$ & $D$ & $\mathrm{M}$ & $\mathrm{D}$ & $M$ & $D$ & $M$ & $\mathrm{D}$ & $\mathrm{M}$ & $D$ & $M$ & $D$ & $\mathrm{M}$ & $\mathrm{D}$ & $\mathrm{M}$ & $D$ & $M$ & $D$ & $M+D$ \\
\hline \multicolumn{27}{|c|}{ Políticas públicas } \\
\hline \multirow{6}{*}{ :00 } & Escola & 1 & & 1 & & 1 & & & & & 1 & 1 & & 3 & & 2 & 1 & 2 & & 2 & & 2 & & 15 & 2 & 17 \\
\hline & Município & & & 1 & & 1 & & 1 & & 3 & & 3 & 1 & 2 & & 6 & & 1 & & 5 & & 2 & 1 & 25 & 2 & 27 \\
\hline & Estado & 1 & & 2 & & 4 & & & 1 & 2 & & 5 & & 2 & & 2 & 1 & & & 3 & & 3 & 2 & 24 & 4 & 28 \\
\hline & Nacional & & & 1 & & & & 2 & 1 & & 1 & & 1 & 1 & & 2 & & 3 & & 2 & 2 & 4 & 2 & 15 & 7 & 22 \\
\hline & Nacionais & & & & & & & & & & & 1 & & & & & & & & & & & 1 & 1 & 1 & 2 \\
\hline & Subtotal & 2 & & 5 & & 6 & & 3 & 2 & 5 & 2 & 10 & 2 & 8 & & 12 & 2 & 6 & & 12 & 2 & 10 & 6 & 80 & 16 & 96 \\
\hline \multicolumn{2}{|c|}{$\begin{array}{c}\text { Gestão de } \\
\text { sistemas/rede }\end{array}$} & & & & & & & & & & & & & & & & & & & & & & & & & \\
\hline \multirow{5}{*}{ 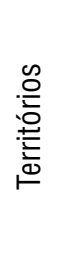 } & Município & & & 1 & & & & 3 & & 2 & & 1 & 1 & 1 & & & & 1 & & 2 & 1 & & & 11 & 2 & 13 \\
\hline & Estado & & & & & 2 & & & & 1 & & & & 1 & & & & & & & & & 2 & 4 & 2 & 6 \\
\hline & Nacional & & & & & & & & & & & & & & & & & & & & & & & & & \\
\hline & Nacionais & & & & & & & & & & & & & & & & & & & & & & & & & \\
\hline & Subtotal & & & 1 & & 2 & & 3 & & 3 & & 1 & 1 & 2 & & & & 1 & & 2 & 1 & & 2 & 15 & 4 & 19 \\
\hline & $\begin{array}{l}\text { estão de } \\
\text { escolas }\end{array}$ & & & & & & & & & & & & & & & & & & & & & & & & & \\
\hline & Escola & 1 & & 1 & & 4 & & 3 & & 1 & & 3 & & 2 & & 6 & & & & & & & & 21 & & 21 \\
\hline & Município & & & 1 & & & & & & 1 & & & & & & & & 2 & & & & 2 & & 6 & & 6 \\
\hline 음 & Estado & & & & & & & 1 & & & & 1 & & & & & & & & & & & 1 & 2 & 1 & 3 \\
\hline 莺 & Nacional & & & & & & & 1 & & & & & & & & & & & & & & & & 1 & & 1 \\
\hline & Nacionais & 1 & & & & & & & & & & & & & & & & & & & & & & 1 & & 1 \\
\hline & Subtotal & 2 & & 2 & & 4 & & 5 & & 2 & & 4 & & 2 & & 6 & & 2 & & & & 2 & 1 & 31 & 1 & 32 \\
\hline & $\begin{array}{l}\text { jireito à } \\
\text { ducação }\end{array}$ & & & & & & & & & & & & & & & & & & & & & & & & & \\
\hline & Escola & & & & & & & & & & & & & 2 & & & & 1 & & 1 & & & & 4 & & 4 \\
\hline & Município & & & & & 1 & & & & & & & & 1 & & & & & 1 & & & & & 2 & 1 & 3 \\
\hline 음 & Estado & & & & & & & & & & & & & & & & & & & & & & & & & \\
\hline 旁 & Nacional & & & & & & & & & & & & & 1 & & & & & & & & & & 1 & & 1 \\
\hline & Nacionais & & & & & & & & & & & & & & & & & & & 2 & & & & 2 & & 2 \\
\hline & Subtotal & & & & & 1 & & & & & & & & 4 & & & & 1 & 1 & 3 & & & & 9 & 1 & 10 \\
\hline & $\begin{array}{l}\text { gislação } \\
\text { normas } \\
\text { Icacionais }\end{array}$ & & & & & & & & & & & & & & & & & & & & & & & & & \\
\hline & Escola & & & & & & & & & & & & & & & & & & & & & & & & & \\
\hline & Município & & & & & & & & & & & & & & & & & 1 & & 1 & & & & 2 & & 2 \\
\hline 음 & Estado & & & & & & & & & & & & & & & & & & & 1 & & & & 1 & & 1 \\
\hline 䛐 & Nacional & & & & 1 & & & 1 & & & & & & & & & & 2 & 1 & & & 1 & & 3 & 2 & 5 \\
\hline & Nacionais & & & & & & & & & & & & & & & & & & & & & & & & & \\
\hline & Subtotal & & & & & & & & & & & & & & & & & 3 & 1 & 2 & & & & 5 & 1 & 5 \\
\hline & Total & 4 & & 8 & 1 & 13 & & 11 & 2 & 10 & 2 & 15 & 3 & 16 & & 18 & 2 & 14 & 2 & 19 & 3 & 12 & 9 & 140 & 24 & 164 \\
\hline
\end{tabular}


Tabela A4 - Número de dissertações de mestrado (M) e teses de doutorado (D) sobre temas de política e gestão da Educação Básica, por categorias temáticas e territórios de referência, por ano - PPG-Edu Santa Catarina - 2000-2010

\begin{tabular}{|c|c|c|c|c|c|c|c|c|c|c|c|c|c|c|c|c|c|c|c|c|c|c|c|c|c|c|}
\hline \multirow{2}{*}{\multicolumn{2}{|c|}{$\begin{array}{c}\text { Ano e Nível/ } \\
\text { Tema e } \\
\text { Território }\end{array}$}} & \multicolumn{2}{|c|}{2000} & \multicolumn{2}{|c|}{2001} & \multicolumn{2}{|c|}{2002} & \multicolumn{2}{|c|}{2003} & \multicolumn{2}{|c|}{2004} & \multicolumn{2}{|c|}{2005} & \multicolumn{2}{|c|}{2006} & \multicolumn{2}{|c|}{2007} & \multicolumn{2}{|c|}{2008} & \multicolumn{2}{|c|}{2009} & \multicolumn{2}{|c|}{2010} & \multicolumn{3}{|c|}{ Totais } \\
\hline & & M & $D$ & $\mathrm{M}$ & D & M & D & M & D & M & D & M & D & M & D & M & D & $\mathrm{M}$ & $D$ & M & D & $\mathrm{M}$ & $D$ & M & $\mathrm{D}$ & $M+D$ \\
\hline \multirow{7}{*}{ 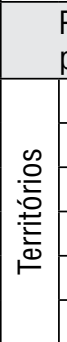 } & $\begin{array}{l}\text { Políticas } \\
\text { públicas }\end{array}$ & & & & & & & & & & & & & & & & & & & & & & & & & \\
\hline & Escola & & & 1 & & & & & & & & & & & & 1 & & 3 & & 4 & & 1 & & 10 & 0 & 10 \\
\hline & Município & & & & & & & 2 & & 4 & & & & 2 & & 2 & & 4 & & 3 & & 2 & 1 & 19 & 1 & 20 \\
\hline & Estado & 1 & & & & 3 & & & & & & & & 2 & & 1 & & & 1 & 1 & & 1 & & 9 & 1 & 10 \\
\hline & Nacional & 1 & & 2 & & & 1 & & & & & & & & 1 & & & & 2 & & & 2 & & 5 & 4 & 9 \\
\hline & \begin{tabular}{|l} 
Nacionais \\
\end{tabular} & & & & & & & & & & 1 & & & 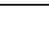 & & & & & & & & 2 & & 2 & 1 & 3 \\
\hline & Subtotal & 2 & & 3 & & 3 & 1 & 2 & & 4 & 1 & & & 4 & 1 & 4 & & 7 & 3 & 8 & & 8 & & 45 & 7 & 52 \\
\hline \multicolumn{2}{|c|}{$\begin{array}{c}\text { Gestão de } \\
\text { sistemas/rede }\end{array}$} & & & & & & & & & & & & & & & & & & & & & & & & & \\
\hline \multirow{5}{*}{ : } & Município & & & & & 2 & & 1 & & & & 1 & & & & 1 & & 1 & & & & 4 & & 10 & & 10 \\
\hline & Estado & & & 1 & & & & 1 & & & & & & & & & & & & & & & & 2 & & 2 \\
\hline & Nacional & & & & & & & & & & & & & & & & & & & & & & & 0 & & 0 \\
\hline & \begin{tabular}{|l|} 
Nacionais \\
\end{tabular} & & & & & & & & & & & & & & & & & & & & & & & 0 & & 0 \\
\hline & Subtotal & & & & & & & & & & & & & & & & & & & & & & & 12 & & 12 \\
\hline \multicolumn{2}{|c|}{$\begin{array}{c}\text { Gestão de } \\
\text { escolas }\end{array}$} & & & & & & & & & & & & & & & & & & & & & & & & & \\
\hline & Escola & & & & & 1 & & 1 & & & & 2 & & 3 & & & & & & 1 & & 2 & & 10 & & 10 \\
\hline$\infty$ & Município & 1 & & & & 1 & & & & & & 1 & & & & 1 & & 1 & & 1 & & 2 & & 8 & & 8 \\
\hline 은 & Estado & & & & & & & & & & & & & 2 & & & & & & & & & & 2 & & 2 \\
\hline 荡 & Nacional & & & & & & & & & & & & & & & & & & & & & & & 0 & & 0 \\
\hline 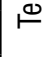 & Nacionais & & & & & & & & & & & & & & & & & & & & & & & 0 & & 0 \\
\hline & Subtotal & & & & & & & & & & & & & & & & & & & & & & & 20 & & 20 \\
\hline & $\begin{array}{l}\text { Direito à } \\
\text { educação }\end{array}$ & & & & & & & & & & & & & & & & & & & & & & & & & \\
\hline & Escola & & & & & & & & & & & & & & & & & 2 & & & & & & 2 & & 2 \\
\hline$\infty$ & Município & & & & & & & & & & & & & & & 1 & & & & & & & & 1 & & 1 \\
\hline 은 & Estado & & & & & & & & & & & & & & & & & & & & & & & 0 & & 0 \\
\hline$\frac{\mathrm{E}}{\mathrm{z}}$ & Nacional & & & & & & & 1 & & & & & & & & & & & & & & 1 & & 2 & & 2 \\
\hline & Nacionais & & & & & & & & & & & & & & & & & & & & & & & 0 & & 0 \\
\hline & Subtotal & & & & & & & & & & & & & & & & & & & & & & & 5 & & 5 \\
\hline & $\begin{array}{l}\text { egislação } \\
\text { normas } \\
\text { ucacionais }\end{array}$ & & & & & & & & & & & & & & & & & & & & & & & & & \\
\hline & Escola & & & & & & & & & & & & & & & & & & & & & & & 0 & & 0 \\
\hline & Município & 1 & & & & & & & & & & & & & & & & & & 1 & & & & 2 & & 2 \\
\hline 음 & Estado & & & & & & & & & & & & & & & & & & & & & & & 0 & & 0 \\
\hline 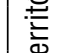 & Nacional & & & & & & & & & & & & & & & & & & & & & & & 0 & & 0 \\
\hline & Nacionais & & & & & & & & & & & & & & & & & & & & & & & 0 & & 0 \\
\hline & Subtotal & & & & & & & & & & & & & & & & & & & & & & & 2 & & 2 \\
\hline & Total & & & & & & & & & & & & & & & & & & & & & & & 84 & 7 & 91 \\
\hline
\end{tabular}

